\title{
Localização em Ambientes Internos Usando a Tecnologia de Comunicação por Luz Visível
}

\author{
Elisa D. R. Lopes ${ }^{* a}$ Lucas C. N. Machado ${ }^{* b}$ \\ Marcelo A. A. Lima ${ }^{* c}$ Leonardo R. Olivi*d \\ Guilherme M. Soares ${ }^{* e}$ \\ * Faculdade de Engenharia Elétrica, Universidade Federal de Juiz de \\ Fora, $M G$. \\ ${ }^{a}$ e-mail: elisa.rossi@engenharia.ufjf.br. \\ ${ }^{b}$ e-mail: lucas.correa@engenharia.ufjf.br. \\ c e-mail: marcelo.lima@engenharia.ufjf.br. \\ ${ }^{d}$ e-mail: leonardo.olivi@engenharia.ufjf.br. \\ e e-mail: guilherme.marcio@ufjf.edu.br.
}

\begin{abstract}
This paper presents a technique for locating people and objects in indoor environments using Visible Light Communication (VLC) technology. In this system, a set of LED luminaires is designed so that each of the luminaires has its luminous intensity modulated according to a known pattern. In this case, the FSK (frequency-shift keying) modulation was used, so that the luminaires were designed to emit a radiation whose frequency is different from the other lighting devices. Considering the differences in the light propagation of each luminaires owing to their distinct positions, each point in the environment will have a different illuminance pattern, which was used to obtain a position reference of that point in the environment. The proposed technique uses the Fast Fourier Transform (FFT) to extract the characteristics of the illuminance waveform from each point. Thereafter, a neural network is used to perform the modeling of a mathematical function that provides the position of the sensor in the environment. In order to validate the proposed technique, a simulator was designed to allow for the evaluation of strategy in a $25-\mathrm{m}^{2}$ room with 4 luminaires.

Resumo: Este artigo apresenta uma técnica para a localização de pessoas e objetos em ambientes internos utilizando a tecnologia de comunicação por luz visível VLC (do inglês, Visible Light Communication). Neste sistema, um conjunto de luminárias LED é projetado para que cada uma das luminárias tenha sua intensidade luminosa modulada de acordo com um padrão conhecido. Neste caso, a modulação FSK (do inglês, frequency-shift keying) foi usada, de modo que as luminárias foram projetadas para emitir radiações com frequências diferentes umas das outras. Considerando as diferenças na propagação da luz de cada uma das luminárias devido às suas posições distintas, cada ponto do ambiente possuirá um padrão distinto da iluminância, que foi utilizado para obter uma referência de posição do referido ponto no ambiente. A técnica de localização utiliza a transformada rápida de Fourier (FFT) para extrair as características da forma de onda de iluminância de cada ponto. Em seguida, uma rede neural é utilizada para realizar a modelagem de uma função matemática que proporciona a posição do sensor no ambiente. A fim de implementar a técnica proposta, um simulador foi concebido no intuito de possibilitar a avaliação da metodologia desenvolvida em uma sala de $25 \mathrm{~m}^{2}$ com 4 luminárias.
\end{abstract}

Keyword: Indoor location, visible light location, artificial neural networks.

Palavras-chaves: Localização em ambientes internos, localização por luz visível, redes neurais artificiais.

\section{INTRODUÇÃO}

A determinação do posicionamento de pessoas, animais e objetos possibilita que diversas tarefas sejam realizadas ou executadas de forma mais eficiente. Por isso, em 1960 o exército americano desenvolveu o GPS (Global Positioning System), um sistema que permite estabelecer o posicionamento de um determinado sensor a partir de satélites

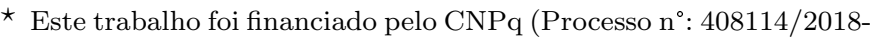
5) e pela FAPEMIG (Processo APQ-01435-18).
}

(Simon et al., 2017). Isso proporcionou a realização de várias tarefas, como por exemplo no setor de transportes, trazendo mais conforto e segurança. Todavia, o GPS não pode ser utilizado com eficiência em ambientes internos, uma vez que seu sinal é atenuado drasticamente pelas paredes (Liu et al., 2007).

Por isso, nos últimos anos a indústria e institutos de pesquisa têm investido no estudo de técnicas para a localização em ambientes internos, cujas principais aplicações são a localização de produtos em armazéns, de médicos 
em hospitais, de homens e animais em operações de resgate (Liu et al., 2007), bem como a localização de robôs(Biswas and Veloso, 2010).

Existem diversas formas de determinar o posicionamento do sensor em espaços fechados, algumas dessas tecnologias são utilizando sonares(Kim et al., 2002), laserscans(Liu and Sun, 2012), redes WiFi(Biswas and Veloso, 2010) e bluetooth(Fischer et al., 2004).

Sistemas que utilizam sonares e laserscans proporcionam resultados satisfatórios, porém seus custos são altos. Já tecnologias baseadas em rádio frequência, como bluetooth e WiFi, são mais baratas, porém possuem baixo desempenho já que o seu sinal sofre reflexão, difração e espalhamento das ondas de raio ( $\mathrm{Li}$ et al., 2017), além de padecerem com interferências eletromagnéticas. Também, para estas, existem lugares onde são proibidas, como em aviões e hospitais (Sahin et al., 2015a). No caso de um sistema de localização baseado na tecnologia VLC, os problemas citados são inexistentes, como o caso da interferência eletromagnética, ou são reduzidos, como é o caso do custo já que os ambientes já contam com luminárias.

Desde 2000, no Japão, uma nova forma de comunicação vem sendo pesquisada, a comunicação por luz visível, do inglês Visible Light Communication (VLC). O transmissor nesse sistema é uma lâmpada de LED, que diferentemente das tecnologias convencionais, possibilitam a variação da intensidade luminosa em taxas muito elevadas, imperceptíveis ao olho humano. Para transmitir os dados a partir da luz, os circuitos de acionamento das luminárias são modificados, de maneira que seja possível incorporar essa funcionalidade de modulação da luz (Komine and Nakagawa, 2004).

Dessa forma, as luminárias de LED são utilizadas para duas finalidades, fornecer luz e comunicação. Isso é mais uma vantagem do sistema VLC, pois ocorre a reutilização da infraestrutura de iluminação para fins de comunicação.

Lançando mão das boas características da tecnologia VLC, alguns trabalhos estudaram sua aplicação na área de localização em ambientes internos. Segundo Pathak et al. (2015), Li et al. (2014) foi o primeiro estudo que propôs a utilização desse sistema, sendo que no referido trabalho, o sinal proveniente da luminária de LED transmite a posição da luminária e a identificação da mesma. A partir do sinal da luminária, um sensor foi utilizado para medir a iluminância e estimar a distância até cada uma das luminárias, de maneira que com essas informações a posição pudesse ser calculada por meio de triangulações. Este sistema obteve uma acurácia inferior a $40 \mathrm{~cm}$.

Em Sahin et al. (2015b) foi desenvolvido um projeto híbrido de técnicas de localização em interiores aplicando VLC, sendo que nele inicialmente é aplicada o método de ângulo de chegada, o qual é implementado com um estimador por mínimos quadrados e determina a localização do sensor. Esta, por sua vez, é fornecida a um filtro de Kalman para determinar uma melhor leitura, em torno de $20 \mathrm{~cm}$ de erro. Então para diminuir o erro é aplicada a técnica de localização por intensidade do sinal recebido, que para lidar com um sistema não linear foi necessário adicionar o método de Newton-Raphson. O trabalho prático foi realizado em uma sala vazia com altura, largura e comprimentos iguais a 3, 4 e 5 metros, respectivamente, e com quatro luminárias instaladas (cada uma em um canto superior da sala). Com isso, foi obtido uma acurácia de 10 $\mathrm{cm}$.

Por outro lado, Wenge et al. (2018) apresentou uma técnica em que foram aplicadas modulações de diferentes frequências nas luminárias de LEDs. A técnica de localização neste caso foi baseada em um algoritmo de reconhecimento de padrões conhecido por KNN, do inglês $K$-NearestNeighbour, treinado de maneira offline a partir dos padrões da FFT dos dados coletados por um sensor de iluminância.

Neste contexto, este trabalho propõe a utilização de um sistema de localização em ambientes interiores baseado na tecnologia VLC. Na técnica proposta, um conjunto de luminárias é distribuído no ambiente de modo que cada uma delas emita luz com uma determinada frequência de modulação. Desta forma, a partir de um sensor localizado no ambiente, a forma de onda da iluminância em um determinado ponto pode ser obtida. Tendo em vista que cada luminária está localizada em um ponto distinto, a contribuição de cada luminária para a iluminância em um determinado ponto do ambiente será diferente. Considerando que cada luminária emite a luz com uma frequência conhecida, é possível utilizar a FFT para obter a contribuição de cada luminária para a iluminância de um determinado ponto, ou seja, para obter as informações que caracterizam uma determinada posição. A partir de tais características, uma Rede Neural Artificial (RNA) foi utilizada para determinar a posição de um ponto no ambiente a partir dos valores da FFT da iluminância medida pelo sensor. Neste trabalho, a análise da característica da iluminância no ambiente foi realizada por meio de simulações computacionais que estimam a propagação da luz a partir da distribuição luminosa de cada luminária utilizando dados do fabricante.

A Figura 1 mostra o fluxograma do algoritmo utilizado para estimar a posição do sensor em um ambiente.

\begin{tabular}{|c|c|}
\hline Dados do Ambiente & Dados da Luminária \\
\hline \multicolumn{2}{|c|}{ Modulação da Intensidade Luminosa } \\
\hline \multicolumn{2}{|c|}{ Cálculo da Forma de Onda da Iluminância no Tempo } \\
\hline \multicolumn{2}{|c|}{ Extração das Características (FFT) } \\
\hline & \\
\hline \multicolumn{2}{|c|}{ RNA } \\
\hline \multicolumn{2}{|c|}{ Posição do Sensor } \\
\hline
\end{tabular}

Figura 1. Fluxograma do algoritmo utilizado.

Neste artigo será encontrado todos os passos pra a realização da proposta na seguinte ordem. Na Seção 2 tem uma descrição de como foi tratada a propagação da luz, e a interpretação da mesma. Na Seção 3 demonstra toda a técnica programada para determinar a posição em que o sensor se encontra no ambiente. Na Seção 4 é apresentado os resultados da simulação desenvolvida para a apresentação da proposta. Por fim, na Seção 5 é feita a conclusão da pesquisa, com comparações com outros artigos e apresentando propostas de trabalhos futuros. 


\section{MODELO DE PROPAGAÇÃO DA LUZ}

Para realizar a proposta apresentada, é necessário desenvolver um modelo de propagação da luz, pois a variação do seu comportamento em cada ponto da sala é o que permite a determinação da posição do sensor. Em algumas aplicações, pode-se assumir que a lâmpada de LED é uma fonte de radiação no padrão Lambertiano (Komine and Nakagawa, 2004). Todavia, esta consideração pode levar a erros significativos, uma vez que na maioria dos casos as fontes não possuem característica Lambertiana. Por isso, para a caracterização da propagação da luz propõe-se a utilização da curva de distribuição luminosa da luminária, obtida por meio de um arquivo disponibilizado pelo fabricante e comumente utilizado para cálculos luminotécnicos.

Para que seja possível apresentar a metodologia de cálculo utilizada neste trabalho, primeiramente é necessária a definição de duas grandezas fotométricas: a intensidade luminosa e a iluminância. A primeira grandeza, representada pelo símbolo $I$, indica o fluxo de energia luminosa de uma fonte em uma dada direção. Por outro lado, a iluminância $(E)$ está relacionada com o fluxo luminoso incidente em uma determinada superfície com sua área (Schreuder et al., 2008). Segundo Costa (2006), Bouguer, um dos principais desenvolvedores das leis fotométricas, determinou uma relação entre essas duas grandezas. A Lei de Burguer define que a Iluminância em um determinado ponto seja dada por:

$$
E=\frac{I}{r^{2}}
$$

onde $r$ é a distância entre a luminária e o sensor. Esse valor de $E$ é para casos em que a intensidade luminosa incida de forma perpendicular a superfície. Para casos em que a fonte luminosa emita luz numa direção oblíqua a superfície horizontal, formando um ângulo $\gamma$ com a normal sobre o plano, tem por definição (Costa, 2006) a iluminância nesse ponto dada por:

$$
E=\frac{I}{r^{2}} \cos \gamma
$$

Portanto, para calcular a iluminância em um determinado ponto, é necessária a obtenção da intensidade luminosa da fonte em uma determinada posição, bem como a distância entre este ponto e a fonte. Esta distância é uma grandeza que pode ser calculada com base nas características geométricas do ambiente simulado. Por outro lado, a intensidade luminosa é obtida a partir do arquivo .IES da luminária.

$\mathrm{O}$ arquivo .IES possui informações como o tamanho da luminária, quantas lâmpadas ela possui, a quantidade de lúmens por lâmpada, bem como os dados relativos à distribuição luminosa da fonte. Os dados de intensidade luminosa são organizadas de acordo com o Sistema de Coordenadas $C \gamma$. Este é descrito como se a lâmpada fosse colocada no centro de uma esfera e a distribuição das intensidades será de acordo com os ângulos $C$ e $\gamma$, suas disposições podem ser observadas na Figura 2(a).

O plano $\gamma$ distribui a intensidade luminosa nas coordenadas y e z, enquanto o plano $\mathrm{C}$ faz sua emissão nas coordenadas x e y. Para determinar então o valor da intensidade

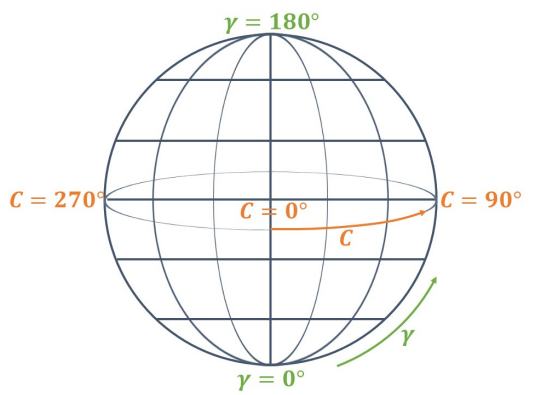

(a) Sistemas de Coordenadas $C \gamma$ (Simons and Bean, 2008).

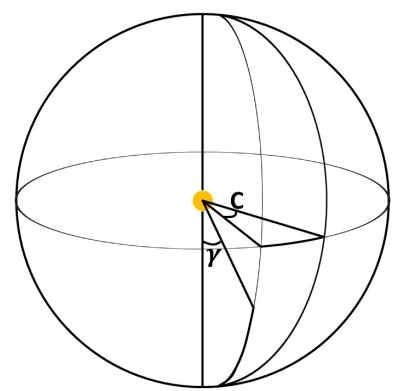

(b) Com uma lâmpada no centro da esfera os ângulos que representam os ângulos que correspondem a direção da seta (Simons and Bean, 2008).

Figura 2. Representação da distribuição luminosa no plano.

luminosa em uma determinada direção é necessário definir o vetor de interseção entre os dois planos, como pode ser observado na Figura 3.

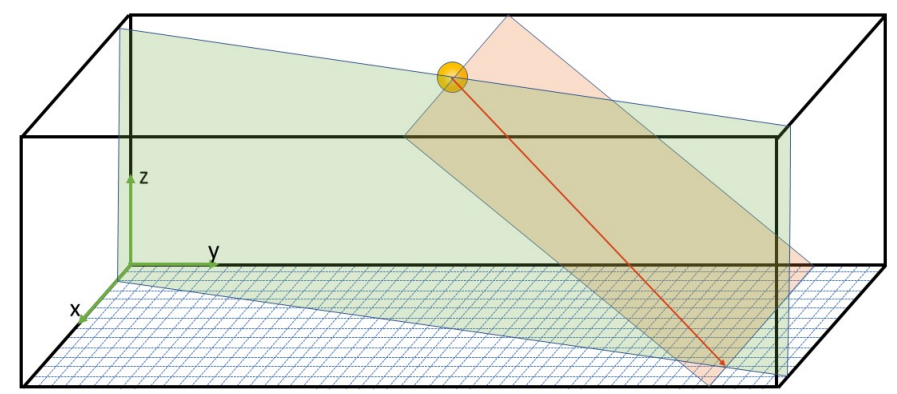

Figura 3. Interseção entre dois planos.

Para calcular a iluminância em cada ponto do ambiente, é inicialmente determinado a quais planos, horizontal e vertical, o sensor pertence. Com esses valores, é possível determinar qual a intensidade luminosa na direção do sensor, que pode ser utilizada em conjunto com a distância $r$ entre o sensor e a fonte em (2) para a obtenção da iluminância.

A princípio, é calculada a iluminância que o sensor recebe de forma direta da luminária, conforme mostrado na Figura 4(a). Em seguida é calculado o valor de iluminância refletida por cada ponto de todas as paredes e objetos contidos na sala, como ilustrado na Figura 4(b). A soma destas duas parcelas resulta no valor final de iluminância que o sensor recebe. 


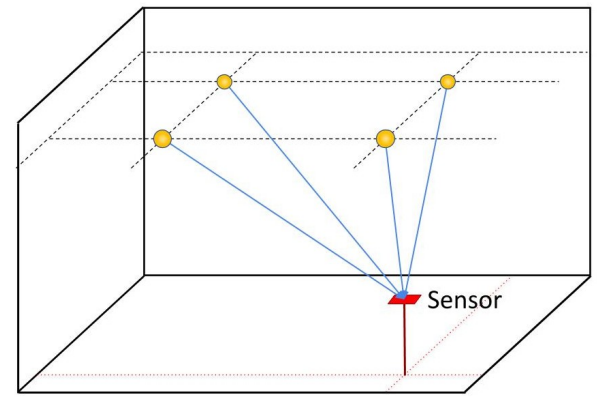

(a) Iluminância Direta

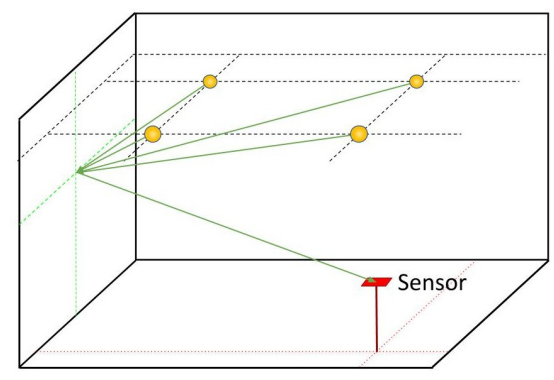

(b) Iluminância Refletida

Figura 4. Tipos de iluminâncias recebidas pelo sensor.

Como demonstrado anteriormente, a iluminância recebida pelo sensor é dada pela Equação (2), assim tem-se que a iluminância total recebida de forma direta é dada por:

$$
E_{\text {Direta }}=\sum_{n=1}^{i} E_{n},
$$

sendo $i$ o número total de luminárias.

A iluminância refletida é proporcionada pelos raios luminosos emitidos pela luminária e que reflete nas paredes e nos demais objetos do ambiente. Esta reflexões redirecionam o raio luminoso para os diversos pontos de leitura do sensor. Deste modo, cada ponto de reflexão na sala pode ser interpretado como uma nova luminária, cuja intensidade luminosa emitida $I_{m}$ será uma parcela da iluminância total neste ponto, sendo proporcional à área de reflexão $W$ e também à refletância da superfície $\rho$, como mostrado em (4) (Komine and Nakagawa, 2004).

$$
I_{m}=\rho . W \cdot \sum_{n=1}^{i} E_{n} \sin \gamma .
$$

Assim como na iluminância de forma direta, da forma refletida a iluminância que atinge a superfície de forma oblíqua contribui apenas com uma parte do seu valor, que está relacionado com o ângulo $\gamma$, porém desta vez é utilizado a função seno pois é calculada a iluminância vertical (Costa, 2006).

Deste modo, para calcular a parcela da iluminância em um ponto relacionada à reflexão das paredes e dos objetos da sala, basta substituir (4) em (2), produzindo:

$$
E_{\text {Refletida }}=\sum_{m=1}^{j} \frac{I_{m}}{r_{m}^{2}} \sin \gamma,
$$

sendo que $W$ é a área de reflexão, $j$ o número total de pontos de reflexão e $r_{m}$ a distância entre o ponto de reflexão e o sensor. Com isso, o valor total de iluminância no sensor será

$$
E_{\text {Total }}=E_{\text {Direta }}+E_{\text {Refletida }} .
$$

\section{LOCALIZAÇÃO UTILIZANDO LUZ VISÍVEL}

\subsection{Modulação da Luz}

O sistema de comunicação a partir da luz visível é feito através da modulação da frequência do fluxo luminoso da luminária, conhecida como Modulação por Chaveamento de Frequência, do inglês Frequency-shift keying(Soares Neto, 2012). A frequência modulada precisa ser superior à percepção do olho humano, já que o objetivo primário das luminárias é a iluminação do ambiente e este não pode ser prejudicado para realizar a comunicação. O sinal modulado da intensidade luminosa da luminária simulado pode ser expressa pela seguinte equação:

$$
I(t)=I_{0} * \operatorname{sgn}\left(\sin \omega_{s} t\right)
$$

em que $t$ é o tempo, $\omega_{s}$ a frequência de modulação e (sgn) a função sinal que retorna o 1 se o argumento for positivo e zero se ele for negativo. Vale ressaltar que neste caso a função sgn é utilizada para produzir uma onda quadrada de frequência angular $\omega_{s}$ a partir de uma onda senoidal com esta frequência.

A ideia proposta neste trabalho consiste em fazer com que cada luminária presente no ambiente emita uma luz modulada com uma determinada frequência. Como cada luminária está localizada em um local diferente do recinto, a propagação da luz de cada uma delas será diferente, pois a distância até cada um dos pontos da região de leitura do sensor será diferente, bem como a intensidade luminosa da luminária naquela direção.

\subsection{Extração das Características}

Como cada lâmpada emite luz com uma frequência de modulação distinta, através da medição da forma de onda da iluminância em um determinado ponto e a aplicação da transformada rápida de Fourier, é possível a obtenção de um conjunto de características daquele ponto, que podem ser representadas em um vetor $\boldsymbol{p}_{\boldsymbol{n}}$ definido por:

$$
\boldsymbol{p}_{\boldsymbol{n}}=\left[A_{1}, A_{2}, \ldots, A_{k}\right],
$$

em que $A_{1}, A_{2}, \ldots A_{k}$ são as amplitudes das iluminâncias associadas às luminárias presentes no ambiente. Desta maneira, é possível definir uma matriz $\boldsymbol{M}$ contendo as características de todos os pontos desejados do ambiente: 


$$
M=\left[\begin{array}{ccc}
p_{11} & \ldots & p_{1 n} \\
p_{21} & \ldots & p_{2 n} \\
\vdots & \vdots & \vdots \\
p_{m 1} & \ldots & p_{m n}
\end{array}\right]
$$

em que $m$ e $n$ correspondem ao número de pontos que podem ser associados ao sensor no eixo $x$ e no eixo $y$, respectivamente.Estas características, por sua vez, podem ser utilizadas para treinar uma rede neural artificial no intuito de obter as coordenadas do ponto a partir da FFT da forma de onda de iluminância em cada ponto. Este procedimento é ilustrado na Figura 5.

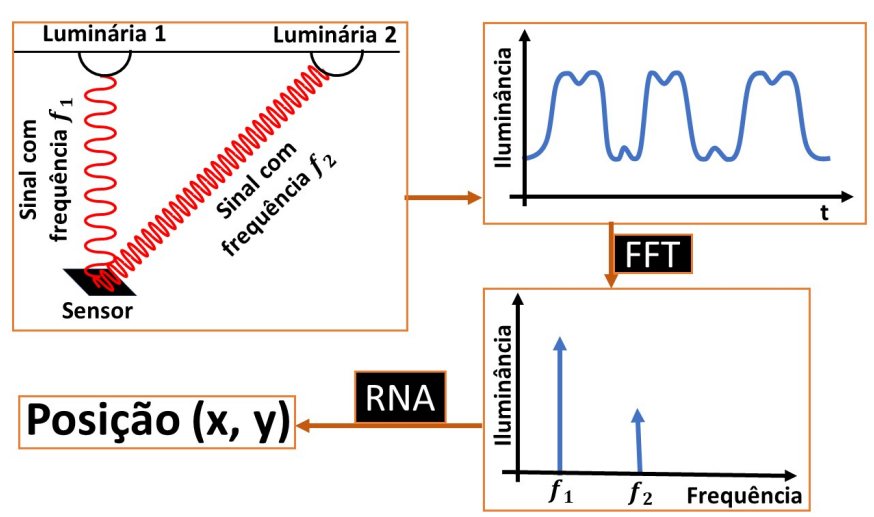

Figura 5. Fases da implementação.

\subsection{Utilização de Redes Neurais Artificiais para a Obtenção da Posição do Sensor}

Redes Neurais Artificiais (RNAs), do inglês Artificial Neural Networks, são uma forma de inteligência computacional inspirada no comportamento do cérebro humano. De acordo com Haykin (2007), a técnica é inspirada nas conexões (sinapses) formadas entre os inúmeros neurônios, generaliza a informação recebida inicialmente (fase conhecida como treinamento) e a partir de então é capaz de determinar saídas para entradas que não eram conhecidas anteriormente.

Como foi mostrado na subseção 3.2, através da FFT é possível determinar a contribuição de cada luminária para a iluminância em um determinado ponto. A contribuição de cada luminária pode ser representada pelo valor da amplitude $A_{i}$, que por sua vez é dependente da intensidade luminosa da luminária $i$ naquele ponto e de sua distância $r$ até o ponto. Deste modo, é possível dizer que o vetor $\boldsymbol{p}_{\boldsymbol{n}}$ representa um conjunto de características de um determinado ponto.

A topologia da RNA utilizada neste trabalho é mostrada na Figura 6. Com 4 entradas, em que cada entrada é a FFT da luminária no ponto $(x, y)$, uma camada oculta que permite uma variação no número de neurônios e duas saídas que condizem com as posições $(x, y)$ do sensor. A rede neural foi treinada e configurada de diversas maneiras diferentes a fim de se obter a proposição mais acertada para os dados oferecidos, inclusive com a técnica de dropout, para evitar o supertreinamento da rede, para e a mesma obtenha uma boa aproximação para pontos não existentes no grupo de treinamento.

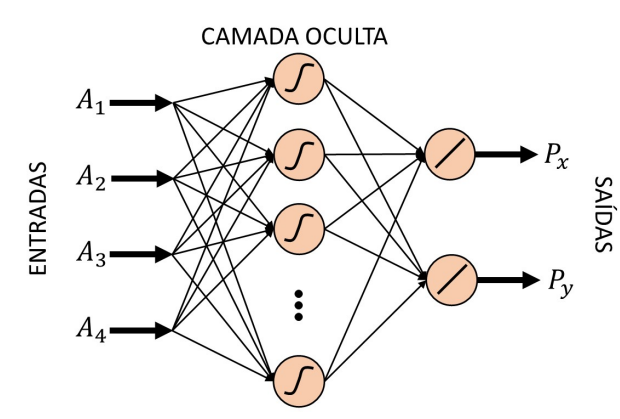

Figura 6. Modelo da rede neural artificial aplicada.

\section{RESULTADOS}

A fim de verificar o desempenho da proposta para a localização de um sensor em ambientes internos, um simulador computacional foi desenvolvido. Este simulador foi concebido com base nas equações apresentadas na Seção 2, bem como em Mandal and Roy (2016).

O ambiente de testes, mostrado na Figura 7, consiste em uma sala com paredes na cor branco neve $(\rho=0.8)$, cuja largura, comprimento e altura são de 5 metros, 5 metros e 3 metros, respectivamente. No ambiente foram instaladas quatro luminárias a cinquenta centímetros do teto, nas posições dadas na Tabela 1.

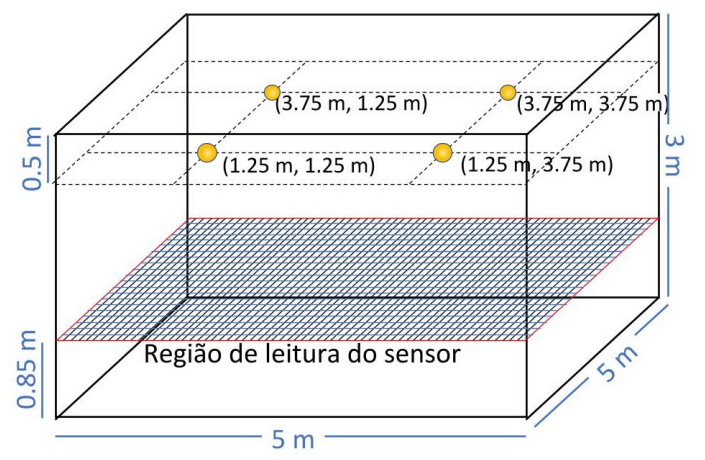

Figura 7. Ambiente simulado.

Tabela 1. Pontos de instalação de cada luminária.

\begin{tabular}{cccc} 
Luminária & $\mathrm{x}$ & $\mathrm{y}$ & $\mathrm{z}$ \\
\hline 1 & $1.25 \mathrm{~m}$ & $1.25 \mathrm{~m}$ & $2.5 \mathrm{~m}$ \\
2 & $1.25 \mathrm{~m}$ & $3.75 \mathrm{~m}$ & $2.5 \mathrm{~m}$ \\
3 & $3.75 \mathrm{~m}$ & $3.75 \mathrm{~m}$ & $2.5 \mathrm{~m}$ \\
4 & $3.75 \mathrm{~m}$ & $1.25 \mathrm{~m}$ & $2.5 \mathrm{~m}$ \\
\hline
\end{tabular}

A discretização do ambiente foi realizada utilizando pequenas regiões de $0.01 \mathrm{~m}^{2}$, sendo que os cálculos foram realizados sempre considerando o ponto central desta região, conforme ilustrado na Figura 8. O valor escolhido para a discretização foi determinado de modo que o sistema possua uma boa exatidão e que o esforço computacional para a solução do sistema não fosse demasiadamente elevado.

A luminária utilizada na simulação é produzida pela empresa Lumicenter Lighting, cujos principais dados são mostrados na Tabela 2. As demais especificações da luminária podem ser encontradas no site do fabricante (Lighting, 2017). 


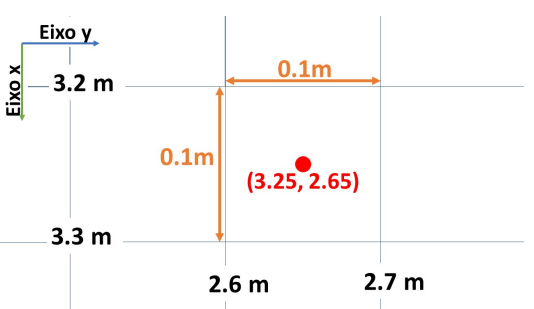

Figura 8. Discretização do ambiente.

Tabela 2. Dados da luminária utilizada na simulação.

\begin{tabular}{cc}
\hline Fluxo & $1000 \mathrm{~lm}$ \\
Potência & $14,5 \mathrm{~W}$ \\
$\mathrm{~N}^{\mathrm{O}}$ LEDs & 1 \\
IRC & $>80$ \\
\hline
\end{tabular}

A região de leitura do sensor também foi representada na Figura 7, sendo esta localizada a $85 \mathrm{~cm}$ do piso. Por outro lado, as frequências de modulação da intensidade luminosa de cada uma das luminárias são mostradas na Tabela 3, enquanto que a Figura 9 ilustra o comportamento das intensidades luminosas de cada uma das fontes. Vale ressaltar que o valor de $I$ utilizado em (7) depende do ponto em análise, conforme explicado na Seção 2.

Tabela 3. Frequências em cada luminária.

\begin{tabular}{cc} 
Luminária & Frequência \\
\hline 1 & $30 \mathrm{kHz}$ \\
2 & $40 \mathrm{kHz}$ \\
3 & $50 \mathrm{kHz}$ \\
4 & $60 \mathrm{kHz}$ \\
\hline
\end{tabular}

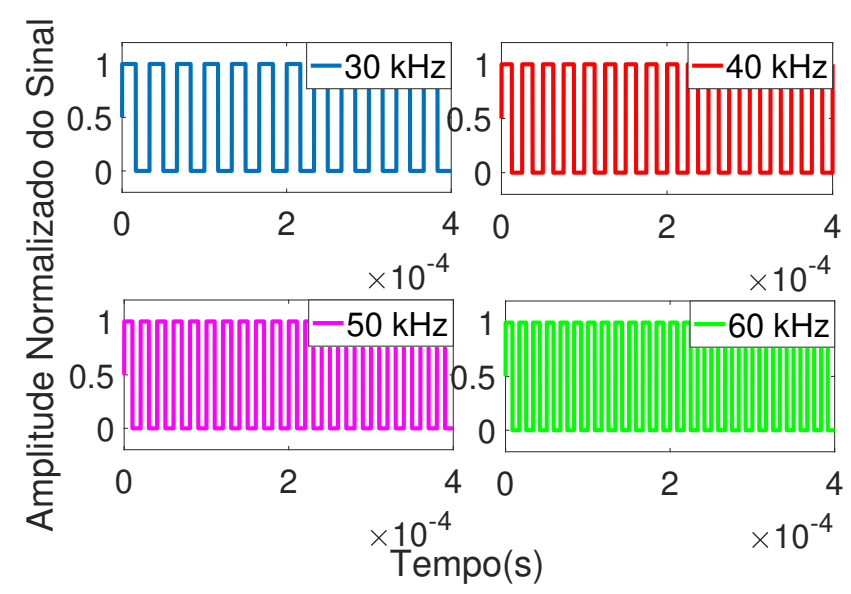

Figura 9. Sinal normalizado emitido por cada luminária de acordo com sua frequência.

Conforme esperado, pode-se verificar a variação da iluminância no ambiente de acordo com o tempo. Em $\mathrm{t}=1 \mu \mathrm{s}$, Figura 10(a), todas as luminárias se encontram ligadas, logo a curva demonstrada apresenta quatro picos de valores da iluminância que correspondem aos pontos abaixo de cada luminária, pois estes são os que possuem a menor distância dos LEDs. No tempo $\mathrm{t}=1575 \mu \mathrm{s}$, na Figura 10(b), apenas duas das luminárias estão emitindo luz.

Diversas curvas de iluminância são armazenadas no decorrer do tempo. Desta maneira, em cada ponto do ambiente

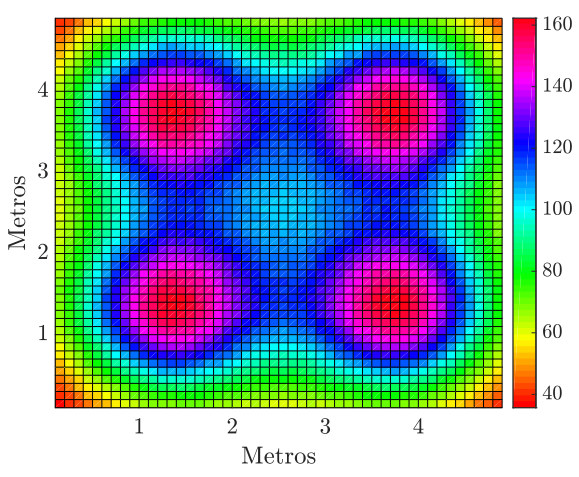

(a) $\mathrm{t}=1 \mu \mathrm{s}$

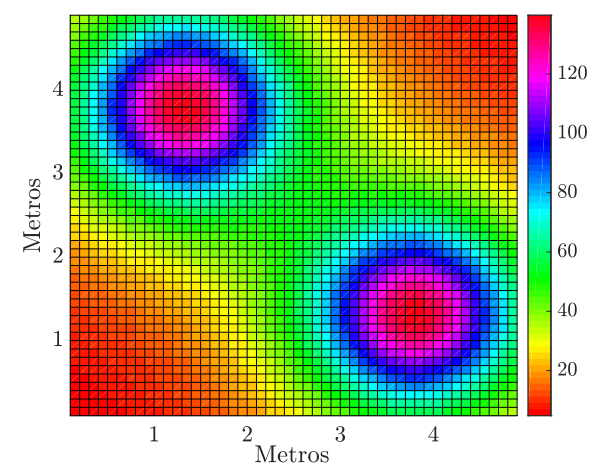

(b) $\mathrm{t}=1575 \mu \mathrm{s}$

Figura 10. Distribuição da iluminância no ambiente.

haverá uma forma de onda da iluminância. A título de exemplo, a Figura 11 ilustra o comportamento de tal variável no ponto $\mathrm{x}=3.2 \mathrm{~m}$ e $\mathrm{y}=3.5 \mathrm{~m}$, cujo posicionamento é ilustrado na Figura 12, que também mostra a localização das luminárias.

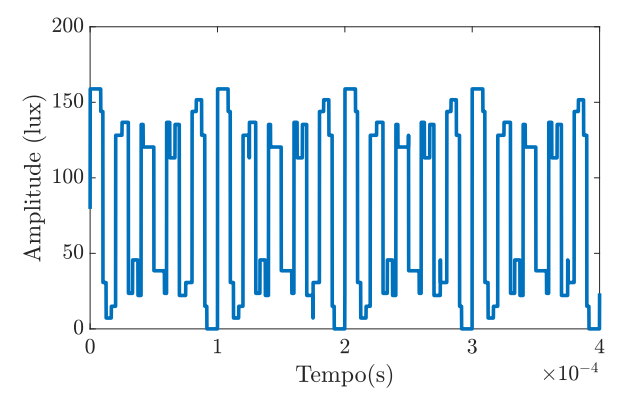

Figura 11. Sinal recebido pelo sensor no ponto escolhido.

A partir do comportamento da iluminância de um ponto no tempo, é possível obter a contribuição espectral de cada luminária aplicando a FFT no sinal medido. O resultado da FFT no ponto $\mathrm{x}=3.2 \mathrm{~m}$ e $\mathrm{y}=3.5 \mathrm{~m}$ é mostrado na Figura 13. Vale ressaltar que, como a intensidade $I$ não varia ao longo do tempo, a FFT também será invariante no tempo e, portanto, pode ser utilizada para caracterizar um determinado ponto no espaço, conforme explicado na Seção 3 .

Utilizando o procedimento descrito na Seção 3, é possível obter os vetores $\boldsymbol{p}_{\boldsymbol{n}}$, necessários para o treinamento de uma RNA. Para se realizar tal procedimento, é necessária a 


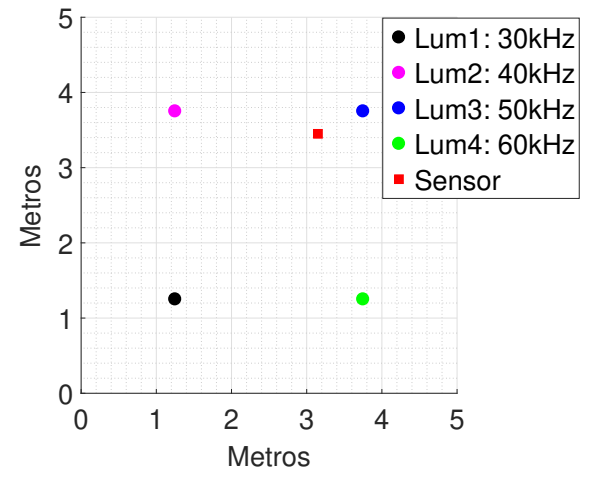

Figura 12. Posição das instalações das luminárias e a posição que o sensor se encontra.

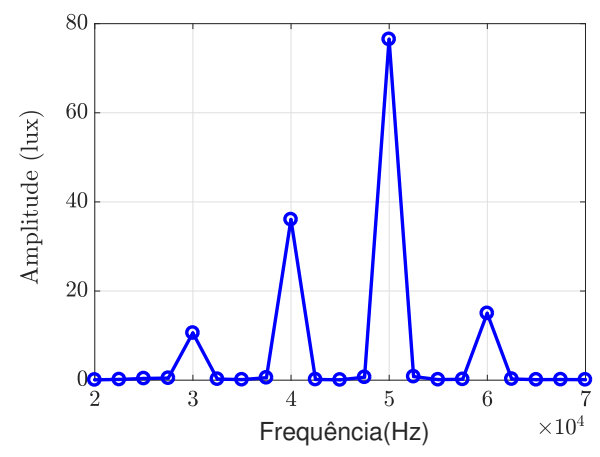

Figura 13. Amplitude recebida no sensor por cada luminária no ponto $\mathrm{x}=3.2 \mathrm{~m}$ e $\mathrm{y}=3.5 \mathrm{~m}$.

definição de qual função de treinamento da RNA que a torna mais eficaz.

Dentre as possibilidades estudadas, as técnicas que obtiveram resultados mais significativos, para treinamentos com 30 neurônios, foram a Leverberg-Marquardt (LM), Bayesian Regularization (BR), Conjugate Gradient with Powell (CGP) e BFGS Quasi-Newton (BFGS). As referidas estratégias apresentaram o menor Erro Médio (EM) dentre as alternativas avaliadas. Ademais, dados como o Desvio Padrão (DP) do erro, o Intervalo de Confiança de $95 \%$ (IC) do erro e o tempo de treinamento da rede neural auxiliaram na escolha da função mais adequada.

Tabela 4. Comparação entre algumas das funções de treinamento.

\begin{tabular}{ccccc} 
Função & EM $(\mathrm{cm})$ & DP $(\mathrm{cm})$ & IC $(\mathrm{cm})$ & Tempo $(s)$ \\
\hline LM & 1.82 & 5.78 & \pm 0.22 & 44.72 \\
BR & 1.7 & 5.84 & \pm 0.23 & 45.33 \\
CGP & 8.82 & 26.5 & \pm 1.04 & 13.68 \\
BFGS & 3.06 & 9.19 & \pm 0.36 & 25.09 \\
\hline
\end{tabular}

Observa-se na Tabela 4 que LM e BR sobressaem significativamente com relação as demais. Então uma avaliação mais específica do comportamento de ambas é demonstrada na Figura 14, que mostra o erro médio que cada função tem de acordo com a variação do número de neurônios.

Para a avaliação da técnica de localização foi utilizada a função de treinamento Leverberg-Marquardt, pois este realizava o treinamento de forma mais rápida que a Bayesian

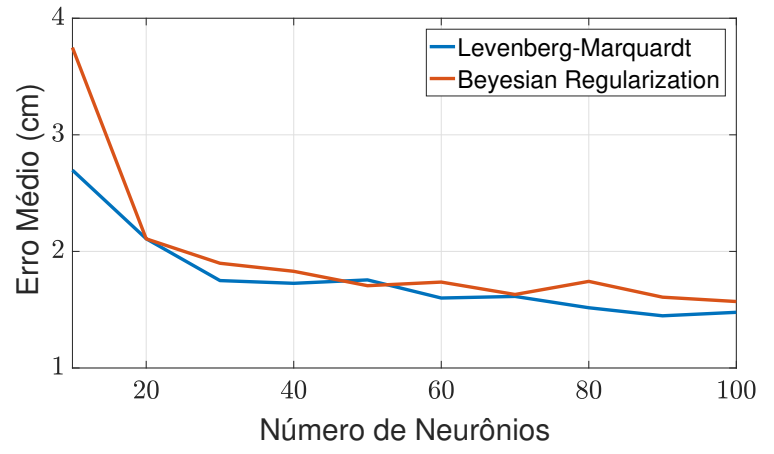

Figura 14. Comparação entre os dois algoritmo que obtiveram resultados mais significativos.

Regularization. O comportamento da rede neural muda de acordo com a variação do número de neurônios da camada escondida, e o excesso desse pode prejudicar os resultados da rede (Haykin, 2007). Nota-se na Figura 14 que com trinta neurônios o sistema já apresentava um erro médio inferior a um centímetro, o que é um resultado bastante interessante para sistemas deste tipo, haja visto que alguns trabalhos na literatura reportaram valores maiores que $\mathrm{Li}$ et al. (2014), Wenge et al. (2018) e Sahin et al. (2015b) . Este erro foi calculado através da distância Euclidiana entre o ponto estimado pela RNA e o ponto real.

A Figura 15 mostra o desempenho do método proposto para a determinação da posição de 100 pontos escolhidos aleatoriamente no ambiente em estudo usando uma rede treinada com 30 neurônios na camada oculta. Como podese observar pela figura, o método proposto foi capaz de estimar a posição dos pontos com uma boa exatidão. O erro médio para esta simulação foi de $1.23 \mathrm{~cm}$ e um desvio padrão de $1.11 \mathrm{~cm}$.

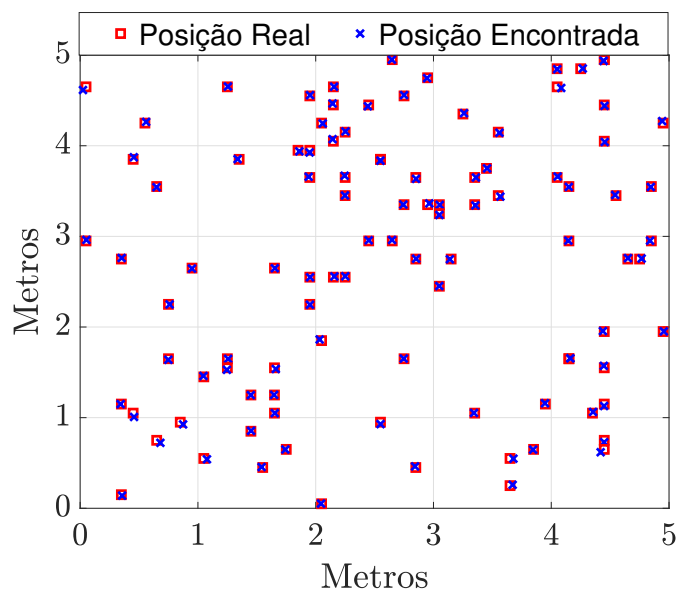

Figura 15. Comparação entre 100 amostras escolhidas de forma aleatória.

A Figura 16 mostra o histograma do erro obtido após o treinamento e validação da RNA, esse erro é a distância euclidiana entre a posição encontrada e a real. Os resultados mostrados na Figura 16 consideram todos os pontos do ambiente, que foram obtidos seguindo o modelo de discretização ilustrado na Figura 8, totalizando um espaço de 2.5 mil pontos. 


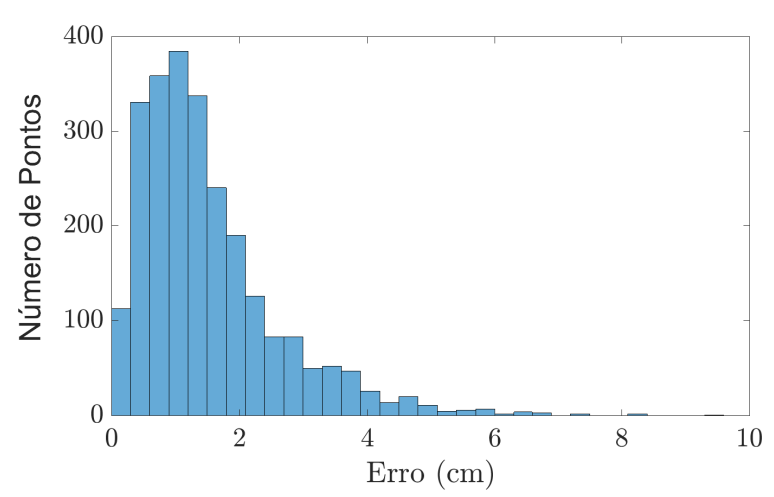

Figura 16. Histograma do erro da RNA.

\section{CONCLUSÃO}

Neste trabalho foi proposta uma técnica de localização para ambientes interiores baseados na tecnologia VLC. O sistema foi concebido para ser capaz de estimar a resposta de um sensor de iluminância com base na simulação da propagação da luz em um ambiente, que foi realizada utilizando como base um arquivo contendo a distribuição de intensidades luminosas de uma luminária real.

A técnica de localização é fundamentada na utilização de um conjunto de luminárias cujas intensidades luminosas são moduladas de acordo com um conjunto de frequências específicas. Deste modo, a partir da aplicação da transformada rápida de Fourier na forma de onda da iluminância em um ponto específico do ambiente, é possível obter um conjunto de informações que caracterizam tal ponto. A partir deste conjunto de características de cada ponto do ambiente e da utilização de uma rede neural artificial, foi possível estimar a localização de um sensor com erros absolutos inferiores a $2 \mathrm{~cm}$ na maior parte do ambiente estudado.

Este resultado mostra que a técnica proposta possui um grande potencial para aplicações que demandam sistemas de localização em ambientes interiores. Dentre as principais propostas para trabalhos futuros destaca-se o teste da técnica proposta para luminárias e ambientes diferentes; verificação da sensibilidade dos resultados para variações na potência da lâmpada, dos coeficientes de reflexão das paredes e outros parâmetros do método; bem como a implementação experimental da proposta.

\section{AGRADECIMENTOS}

Os autores gostariam de agradecer ao CNPq, FAPEMIG, a Capes e a UFJF pelo suporte financeiro e estrutural.

\section{REFERÊNCIAS}

Biswas, J. and Veloso, M. (2010). Wifi localization and navigation for autonomous indoor mobile robots. In 2010 IEEE international conference on robotics and automation, 4379-4384. IEEE.

Costa, G.J.C.d. (2006). Iluminação econômica-cálculo e avaliação, $4^{\mathrm{a}}$ edição. Porto Alegre: EIDPUCRS-Coleção Engenharias.

Fischer, G., Dietrich, B., and Winkler, F. (2004). Bluetooth indoor localization system. In Proceedings of the 1st
Workshop on Positioning, Navigation and Communication, $147-156$.

Haykin, S. (2007). Redes neurais: princípios e prática. Bookman Editora.

Kim, J., Pearce, R.A., and Amato, N.M. (2002). Robust geometric-based localization in indoor environments using sonar range sensors. In IEEE/RSJ International Conference on Intelligent Robots and Systems, volume 1, 421-426. IEEE.

Komine, T. and Nakagawa, M. (2004). Fundamental analysis for visible-light communication system using led lights. IEEE transactions on Consumer Electronics, 50(1), 100-107.

Li, L., Hu, P., Peng, C., Shen, G., and Zhao, F. (2014). Epsilon: A visible light based positioning system. In 11th \{USENIX\} Symposium on Networked Systems Design and Implementation (\{NSDI\} 14), 331-343.

Li, Z., Jiang, M., Zhang, X., Chen, X., and Hou, W. (2017). Space-time-multiplexed multi-image visible light positioning system exploiting pseudo-miller-coding for smart phones. IEEE Transactions on Wireless Communications, 16(12), 8261-8274.

Lighting, G.L. (2017). PF110-S1000840. http:// Www.lumicenteriluminacao.com.br/catalogo/ pf110-s-p457/. [Online; acessado em 01-Abril-2019].

Liu, H., Darabi, H., Banerjee, P., and Liu, J. (2007). Survey of wireless indoor positioning techniques and systems. IEEE Transactions on Systems, Man, and Cybernetics, Part C (Applications and Reviews), 37(6), 1067-1080.

Liu, Y. and Sun, Y. (2012). Mobile robot instant indoor map building and localization using $2 \mathrm{~d}$ laser scanning data. In 2012 International Conference on System Science and Engineering (ICSSE), 339-344. IEEE.

Mandal, P. and Roy, B. (2016). Matlab simulation of indoor general lighting with luminaire ies file. Light 8 Engineering, 24(2).

Pathak, P.H., Feng, X., Hu, P., and Mohapatra, P. (2015). Visible light communication, networking, and sensing: A survey, potential and challenges. IEEE communications surveys \& tutorials, 17(4), 2047-2077.

Sahin, A., Eroglu, Y.S., Güvenc, I., Pala, N., and Yüksel, M. (2015a). Hybrid 3-d localization for visible light communication systems. Journal of Lightwave Technology, 33(22), 4589-4599.

Sahin, A., Eroglu, Y.S., Güvenc, I., Pala, N., and Yüksel, M. (2015b). Hybrid 3-d localization for visible light communication systems. Journal of Lightwave Technology, 33(22), 4589-4599.

Schreuder, D. et al. (2008). Outdoor lighting: physics, vision and perception. Springer.

Simon, G., Zachár, G., and Vakulya, G. (2017). Lookup: Robust and accurate indoor localization using visible light communication. IEEE Transactions on Instrumentation and Measurement, 66(9), 2337-2348.

Simons, R.H. and Bean, A.R. (2008). Lighting engineering: applied calculations. Routledge.

Soares Neto, V. (2012). Telecomunicacões-sistemas de modulacão-uma visão sistêmica. Editora: Erica.

Wenge, T., Chew, M., Alam, F., and Gupta, G.S. (2018). Implementation of a visible light based indoor localization system. In 2018 IEEE Sensors Applications Symposium (SAS), 1-6. IEEE. 